\title{
A Critical Review of Regenerative Therapies for Shoulder Rotator Cuff Injuries
}

\author{
Michael Dickinson $^{1} \cdot$ Samantha L. Wilson ${ }^{2}$ (D
}

Accepted: 7 November 2018 / Published online: 7 December 2018

(C) The Author(s) 2018

\begin{abstract}
Rotator cuff tears can cause pain and weakness in the shoulder and affects a wide range of individuals. Conventional repair consists of operative surgical techniques or conservative treatments including physiotherapy; however, there is still a big issue in the increased risk of re-tearing of the tendons. Regenerative therapies are looking for new and novel ways of improving the healing of tendon injuries. Platelet-rich plasma (PRP) uses the patient's own blood in a concentrated form, to supply the repair site with various growth factors that promote the healing response; however, research shows conflicting evidence about the efficacy and effectiveness of PRP. Stem cell research is slowly increasing use of human patients in research trials and is showing significant results in improving and reducing the re-tear rate. Tissue engineering encapsulates a range of techniques such as scaffolds and patches to augment repair of the rotator cuff tendon, and research has shown that such techniques can provide protection and assistance to the repairing tendon to improve results. This review aims to critically compare and evaluate recent research and provide possible future directions.
\end{abstract}

Keywords Platelet-rich plasma $\cdot$ Stem cells $\cdot$ Tissue engineering $\cdot$ Mesenchymal stem cells $\cdot$ Scaffolds $\cdot$ Augmentation $\cdot$ Re-tear

\section{Introduction}

The rotator cuff (Fig. 1) is a group of four muscles (the supraspinatus, infraspinatus, teres minor, and subscapularis) in the glenohumeral joint (GHJ). Rotator cuff tears (Fig. 1) can cause pain and weakness in the shoulder. It is an injury that plagues the general public ( $4 \%$ of under 40 's; $53 \%$ of over 60 's) and athletes alike [1]. Repair is often either non-operative, utilising physiotherapy to maintain range of movement, rotator cuff, and deltoid strength, as well as scapula-stabilising or operative, which employs surgical methods to repair and reattach the tendon; however, it can lead to re-tearing, persistent pain, and stiffness [2].

This article is part of the Topical Collection on Medicine

Samantha L. Wilson

s.wilson2@lboro.ac.uk

1 National Centre for Sport and Exercise Medicine, School of Sport, Exercise and Health Sciences, Loughborough University, Epinal Way, Loughborough, Leicestershire LE11 3TU, UK

2 Centre for Biological Engineering, Wolfson School of Mechanical, Electrical and Manufacturing Engineering, Loughborough University, Epinal Way, Loughborough, Leicestershire LE11 3TU, UK
Classification of a rotator cuff injury is often based on the size of the tear (Table 1) [2]. Healing rates are poor for surgical repairs of large and massive tears. Novel techniques are looking at enhancing the tendon tissue regeneration. Such techniques include the use of platelet-rich plasma (PRP), a substance that when injected releases various growth factors that play a role in tissue repair; the use of stem cells, usually mesenchymal stem cells (MSCs), which have the ability to self-renew and differentiate to various tissues [3]; and the use of tissue-engineered approaches which use various scaffolds and patches to augment repair $[4,5]$. The aim of this review is to critically analyse the new regenerative therapies that have been used recently to facilitate healing following rotator cuff injuries.

\section{Novel Strategies Used in Rotator Cuff Regeneration}

Regenerative therapies utilised in rotator cuff regeneration all differ in their application. PRP therapy is a form of prolotherapy and requires patients to undergo injections, often post-surgery; stem cell therapy requires the patient to undergo surgery, with stem cells being applied following surgery; and tissue engineering is a relatively new approach and covers a 
Fig. 1 Healthy anterior and posterior views of the rotator cuff muscles (left). Example of a rotator cuff tear (supraspinatus) (right)
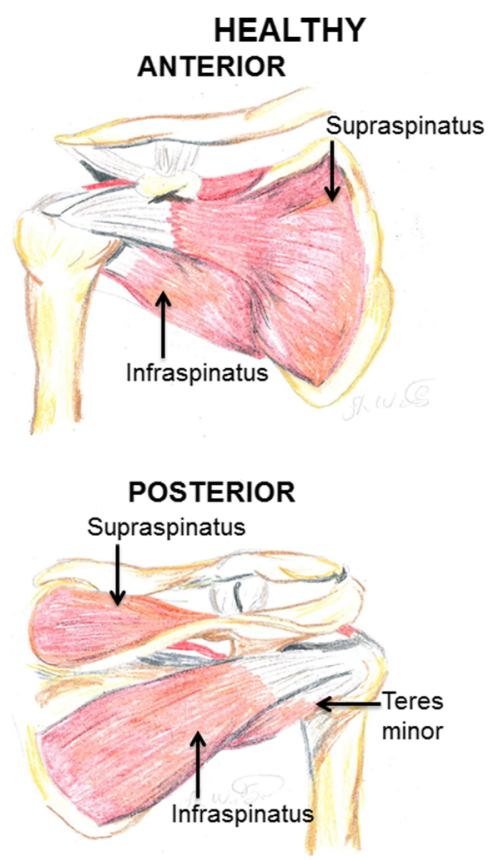

TEAR

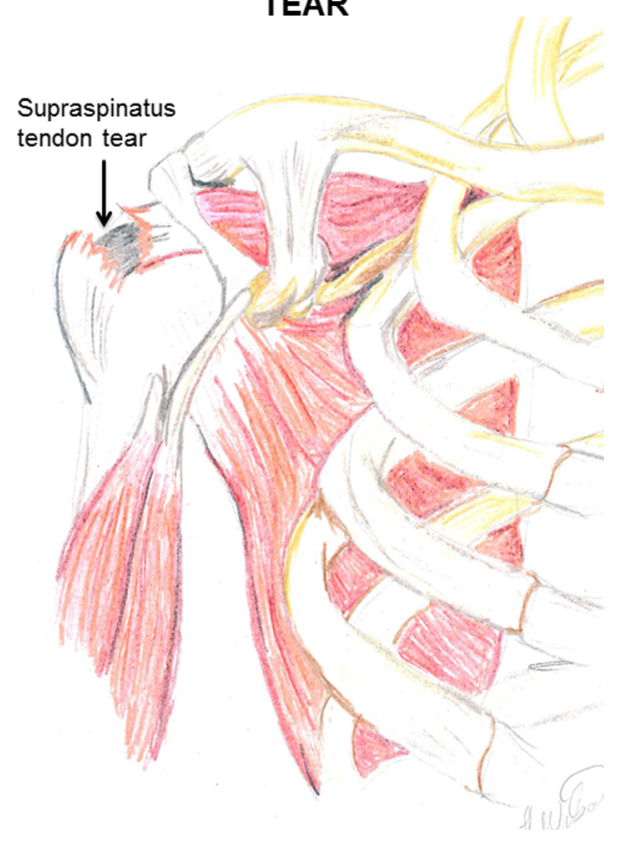

range of techniques, such as utilising scaffolds and patches to augment surgery. PRP has predominantly been studied on humans, although results are still not clear as there are numerous contradictory findings. Stem cell research has been shown to reduce the rate of re-tears, although there have currently been limited studies on humans to date. Tissue engineering is providing novel techniques with very promising results, although not one 'gold-standard' has been determined for rotator cuff repair. Research has used a variety of scores and scales (Table 2) to assess quality of repair.

PRP has been utilised to augment surgical repair of medium and large tears [6], resulting in a significantly improved repair, as there was a significant improvement (decrease) in the re-tear rate. Pandey et al. [7] investigated the use of PRP to aid in the healing of large and massive rotator cuff repairs [7]. Similarly, a decreased re-tear rate was found 24 months postsurgery for large tears, when compared to a control group of 50 patients. Results also demonstrated that PRP can reduce pain and increase functionality, strength, and vascularisation post-surgery.

Hernigou et al. [8] and more recently Kim et al. [9] have provided the most comprehensive research when focusing on stem cell therapy $[8,9]$, both indicating that stem cells can improve rotator cuff surgery, especially improving

Table 1 Classification of rotator cuff tears by size

\begin{tabular}{ll}
\hline Classification & Tear size $(\mathrm{cm})$ \\
\hline Small & $<1$ \\
Medium & $1-3$ \\
Large & $3-5$ \\
Massive & $>5$ \\
\hline
\end{tabular}

(decreasing) re-tear rates post-surgery, which is one of the main concerns following surgical tendon repair. Any disruption (re-tear) in the initial healing stage can interfere with rehabilitation strategies, resulting in a prolonged time frame before patients can resume full activities (work or sport).

Tissue engineering approaches have utilised various scaffolds and patches to augment healing, such as 'GraftJacket' [10]. Results show that the use of this acellular human dermal matrix augmentation can improve the quality of repair, as more intact rotator cuffs were found $(85 \%$ compared to $40 \%$ ), as well as improving various scores on pain and function, compared to surgical repair with no additional augmentation.

\section{Critique of Techniques Used in Rotator Cuff Regeneration}

\section{Platelet-Rich Plasma}

Of all the regenerative techniques that will be critiqued in this review, the use of platelets has been investigated in humans more than studies in stem cell research and tissue-engineered approaches. This could suggest that the use of platelets is already becoming an accepted practice since it carries less ethical issues.

Literature demonstrates (Table 3) that there are mixed, sometimes, conflicting results, following the use of PRP. Studies that adopted a human model reported a significant improvement in scores (Table 2) such as the VAS, ConstantMurley score, UCLA, and shoulder external rotation $[6,7,13$, $22]$. When evaluating the actual injuries that were reported in 
Table 2 Scores and scales used to evaluate intervention effectiveness

\begin{tabular}{|c|c|c|}
\hline Score/Scale & Measure & Key points \\
\hline Visual analogue scale (VAS) & Pain & Subjective, a $0-10$ scale, patients mark the scale. \\
\hline Constant-Murley score (constant) & Functionality & $\begin{array}{l}\text { Subjective and objective. Four subscales: pain; } \\
\text { activities of daily living, strength, and range } \\
\text { of movement }\end{array}$ \\
\hline $\begin{array}{l}\text { University of California, } \\
\text { Los Angeles (UCLA) }\end{array}$ & Strength and function & $\begin{array}{l}\text { Subjective and objective. Measures, forward } \\
\text { elevation, strength, pain, satisfaction, } \\
\text { and function }\end{array}$ \\
\hline $\begin{array}{l}\text { American Shoulder and Elbow } \\
\text { Surgeons (ASES) }\end{array}$ & Pain and function & $\begin{array}{l}\text { Subjective and objective. Includes } \\
\text { physician-rated section. Measures pain, } \\
\text { function, and instability. }\end{array}$ \\
\hline
\end{tabular}

these studies, participants were only included if they had suffered rotator cuff tears, whereas studies that reported no significant differences often only looked at tendinopathy [11, 14]. This may suggest that PRP could be more effective in the treatment of a full tear. Perhaps during tendinopathy, there has already been some degree of healing, meaning that the additional growth factors and stimulation PRP promotes are not effective and can only help in the initial stages of 'tendonbone' formation.

This is verified by animal studies (rabbits and rats) that created and repaired acute tears, where all results showed significant improvement with the use of PRP. Improvements included an increase in vascularisation and cellularity within 4 weeks [20] post-treatment and fibronectin production [19], suggesting that PRP does benefit healing, however, only in the initial stages. These studies used animal models (rabbits and rats); thus, the results cannot be completely generalised to humans.

Interestingly, there have been human studies that investigated the use of platelet-rich fibrin (PRF) instead of the more conventional PRP. Platelet-rich fibrin (or platelet-rich fibrin matrix (PRFM)) is a variation of PRP and involves activation of the fibrin-clotting cascade and a second centrifuge stage [15]. As PRF is already formed into a matrix, it traps some non-activated platelets, essentially delaying the release of platelets and providing a longer time frame for platelet delivery. Yet again, results were varied, with Antuña et al. [23] showing improvements whereas Rodeo et al. [15] and Weber et al. [16] reported no significant differences to healing. Although Antuña and colleagues (Antuña et al. [23]) did report significant differences in shoulder function (constant score increased) and pain scores (VAS decreased), their results might not carry much statistical power as the population size of their study was small $(n=28)$. These findings could suggest that the use of PRF does not improve the healing of the tendon-bone interface, perhaps due to gaps that are left behind once the matrix has dissolved [15].

The majority of studies (animal models that found a significant improvement) reported an increase in the maximum load to failure. This suggests that PRP can create a stronger 'bond' than that created naturally. This could be linked to the increased vascularity reported earlier, as the repair site would experience an increase in growth factors and inflammatory cells to aid in the reparative and remodelling stages.

\section{Stem Cells}

When evaluating the use of stem cells (Table 4) in the regenerative therapies of rotator cuff injuries, there are few studies that have investigated the application of stem cells in humans, although they have shown promising results. As early as 2012, Gomes et al. found that an injection of autologous bone marrow (BM) mononuclear cells following surgery increased patient's functional status [34]. However, since there was no control group, results could only be compared to histological data; since the study was not blinded, there was the possibility of bias in the results; coupled with small population size, the statistical relevance of these results is questionable.

Of the three human studies included in this review, only one did not use BM-derived MSCs. Kim et al. [9] utilised adipose tissue (AT)-derived MSCs in combination with fibrin glue, delivering mechanical aid whilst delivering MSCs. BM is considered to be a favourable source of MSCs [35] and is still being found to give the most beneficial effects in tendon healing [36]. However, sourcing MSCs from AT is less painful, and there is a greater concentration of stem cells, which would be desirable, as Hernigou et al. [8] alluded to. The number of MSCs is important, since fewer MSCs included in the applied solution may result in reduced tendon integrity, which in turn could come full circle and result in a re-tear. The study by Kim et al. [9] shows an alternative to BM as a source for stem cells in the regenerative repair of the human rotator cuff.

When comparing the animal studies that have used stem cells to aid the healing, the majority have shown fairly positive results, with only two studies finding no significant differences. Of these two, one was an early study [33, 37] which included one of the shortest follow-up times of a maximum of 4 weeks, leaving the possibility that they might have 


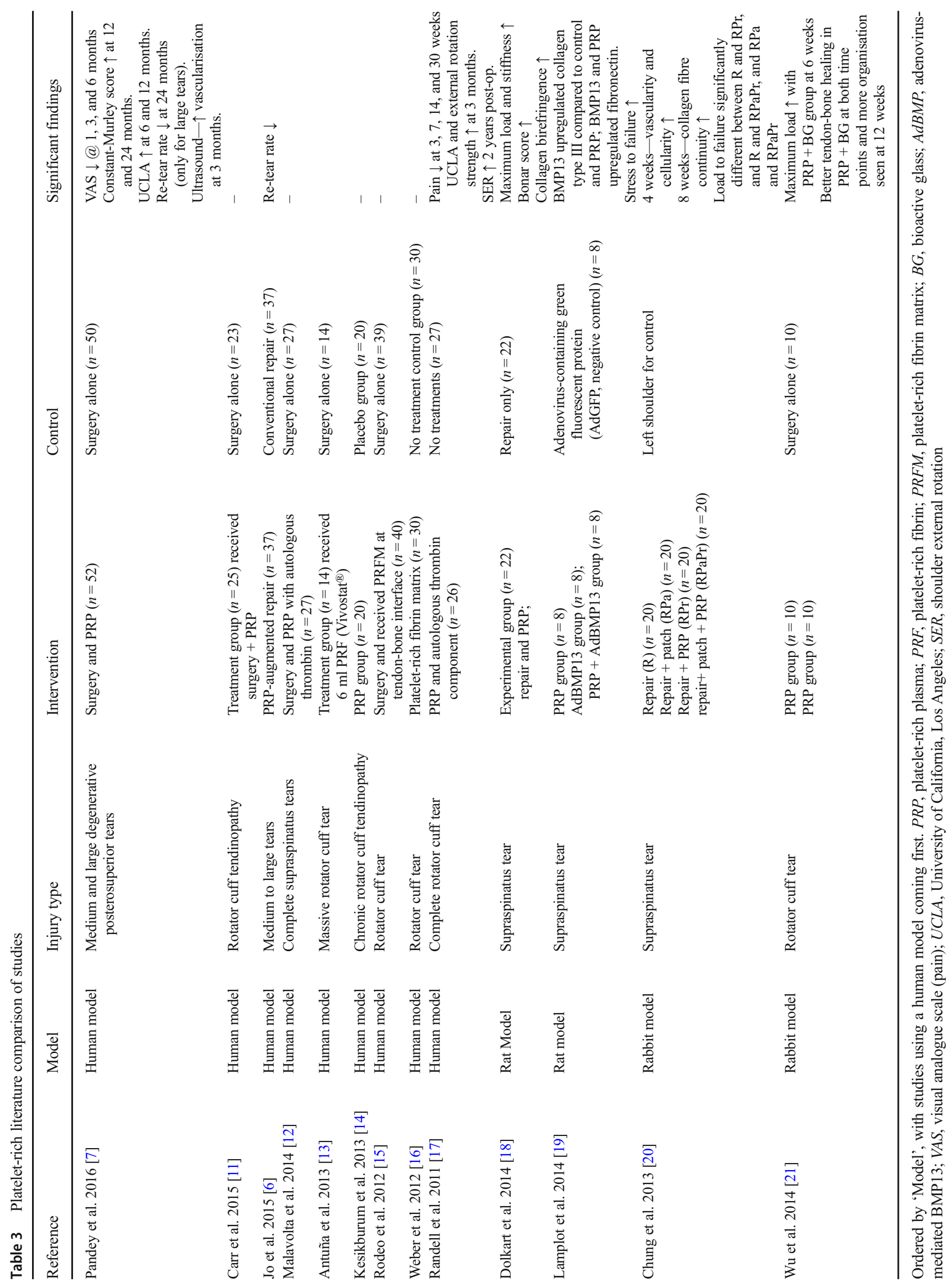




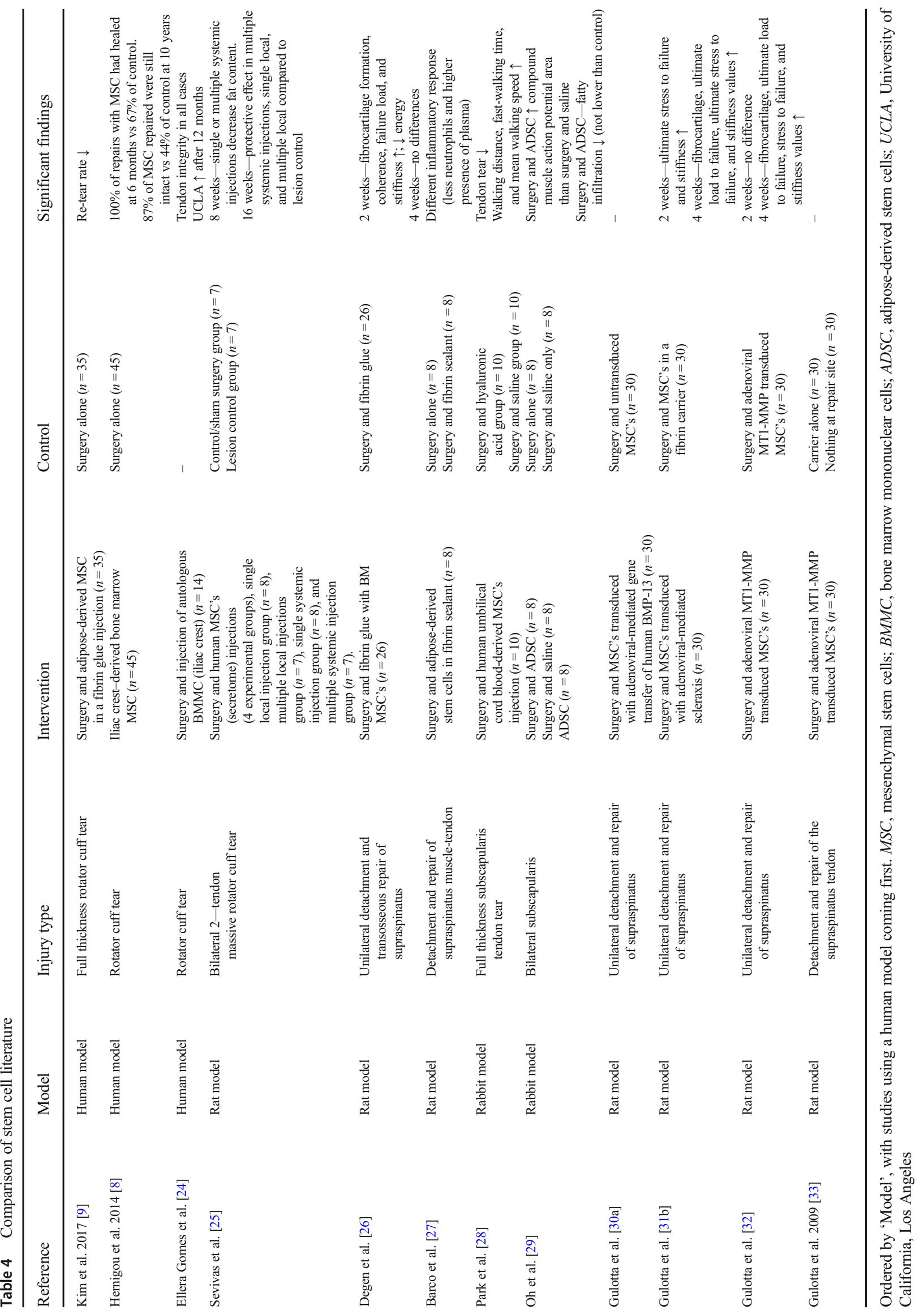




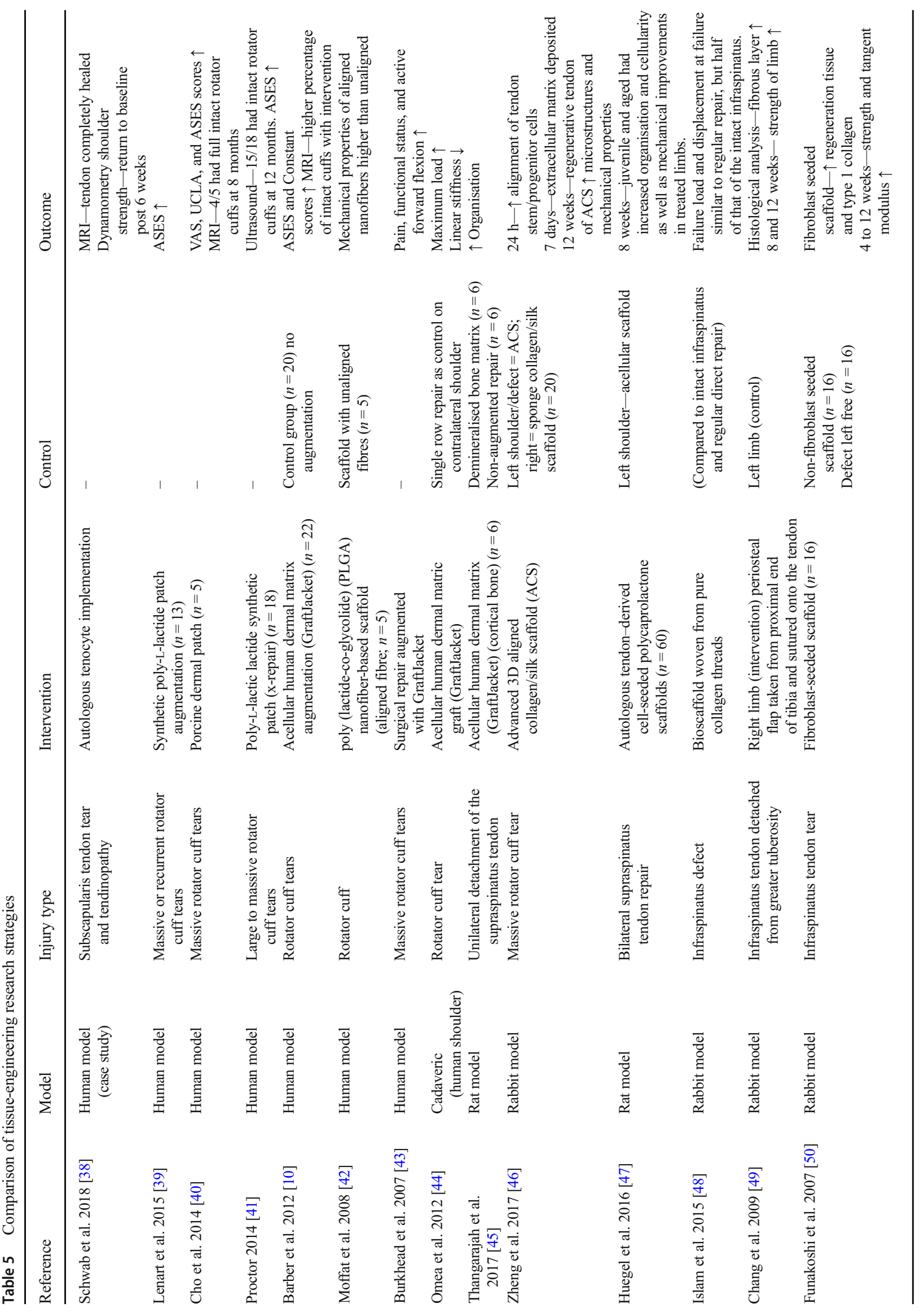




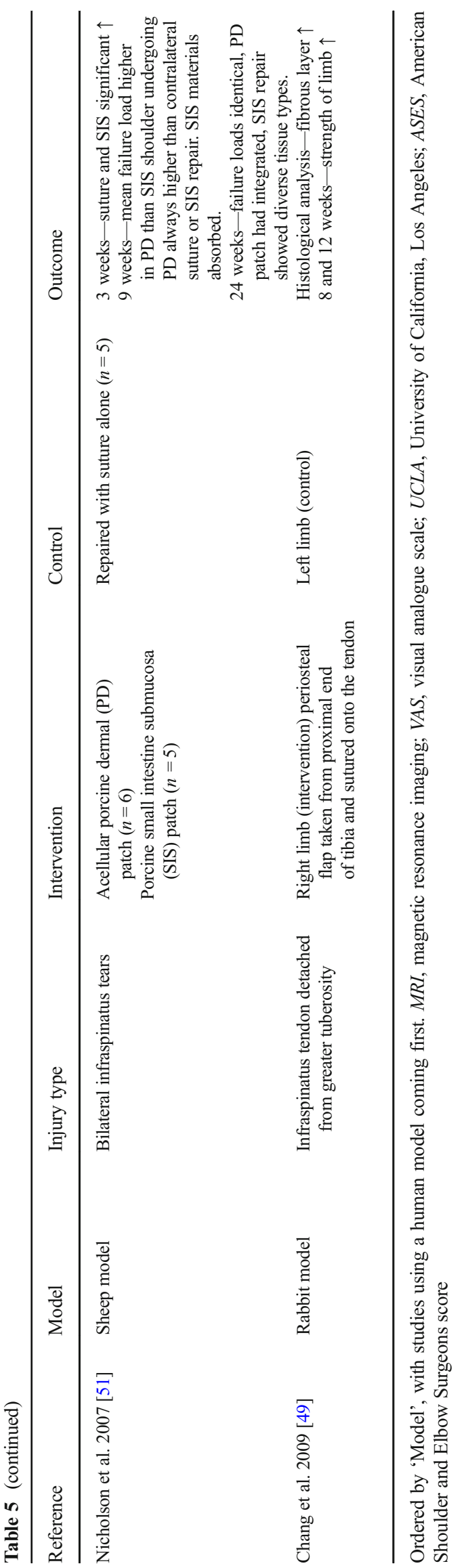

overlooked any potential prolonged benefits. Further study by Gulotta (2011a) looked at two different variations of MSCs, demonstrating that there was no difference between these variations. However, following the trend from other research (Table 4), it would be wise to assume that there would be some additional benefits in using MSCs than just surgery alone.

It is possible to see (Table 4) animal studies show varying degrees of success and analyse a range of different outcome measures, for example maximum load at failure, cartilage formation, and fat content. Kim et al. [9] suggested that follow-up should be 12 months at least, as most re-tears happen within 6 months [35]. With the animal studies having a short follow-up period and providing potentially subjective histological analysis, data may be missing the requirements for long-term recovery; however, more human trials would need to look at these factors in similar time frames to confirm that. Additionally, rehabilitation that humans undertake postsurgery could pose as an added risk for re-tears.

\section{Tissue Engineering}

When examining the numerous tissue-engineering approaches in the regeneration of tissue, most have utilised grafts and scaffolds, with most studies presented in this review showing positive results (13 of 15 studies presented in Table 5).

Autologous tenocyte implementation (ATI) is a novel technique that has recently been used successfully in the treatment of a rotator cuff tear and tendinopathy [47]. This was a case study documenting a single participant; thus, it may not carry much statistical power. Coupled with this, the participant had already undergone PRP, so there is the possibility that healing, at least to some extent, had already occurred. As ATI is an injection-based therapy, there is no need for surgery which would require more time out and rehabilitation; it also cancels out any chance of the repair re-tearing. As such, ATI could provide an ethical alternative, as it uses autologous tenocytes to create a healing response by utilising growth factors, interleukins, and organised collagen fibres (Schwab et al., [38]).

In 2016, Huegel et al. performed a similar, autologous tendon-derived cell therapy on rats, and also added the use of scaffold [43]. Results showed an increase in fibre organisation, cellularity, and mechanical improvements which could, to some extent, confirm results from Schwab and colleagues (Schwab et al. [38]). Interestingly, the use of autologous tendon cells could have a possible 'age effect'. Results in rats showed that it only worked in the young and old, suggesting that there needs to be an imbalance in the tendon (growing/ageing). The case study here was a 28 -year-old male, which poses the question: when does ageing start to effect tendons? 
Previous studies (Table 5) demonstrate that much of the research that examines human models demonstrated significant findings. However, there were no controls in five of the studies [38-41, 47], which makes comparisons difficult since they will have to be made via comparison of histological data, giving room for different methodologies and techniques to influence results. Although the findings show that shoulder function has been improved, this could suggest that no matter which engineering approached is used, shoulder function will improve.

Two of the more popular augmentation devices used were the 'GraftJacket' and the poly-L-lactic acid synthetic patch (or 'x-repair') [10, 39, 41, 42, 44]. GraftJacket worked in all but one study; however, that particular instance used rat models, whereas when used on human, it was found to significantly improve the repair. It is perhaps more established, since it has been used in surgeries since 2003 [39]. The 'GraftJacket' potentially helps increase vascularisation at the repair site through its structure and slowly dissolves once healing is complete. The poly-L-lactic acid synthetic patch unanimously found significant improvements with its use, although no control population was used, which does not rule out the possibility of extraneous factors influencing healing; it acts in tandem with the tendon whilst providing support and protection. It is not possible to say which method is better right now; more research is required including double-blinded, controlled studies. However, current findings suggest that as long as the patch can help prevent the creation of scar tissue, which causes weakness [5], then the augmentation has the chance to improve rotator cuff tear.

This is verified when evaluating research conducted on animals (Table 5), as most studies use different patches and scaffolds, but all find improvements, whether it is failure load, fibre organisation, vascularity, or even strength. Findings suggest that additional assistance to the tendon during the initial stages of healing, which prevents the accumulation of scar tissue, makes for an overall better tendon repair.

\section{Conclusion}

Regenerative therapies have been focused on improving the healing of the rotator cuff and decreasing the chance of retears. Some techniques, such as PRP, have thus far been unable to present clear, concise findings and demonstrate an ability to consistently and effectively improve the repair. Stem cell research is showing positive results; however, more work is required on human patients to be able to confidently say this is the case; also, future work should look at the use of adipose MSC's as there are a few potential benefits to using these, such as a less painful sourcing and a greater total concentration of MSCs available. Overall, tissue-engineering approaches appear to be the most effective at improving healing.
Future research needs to include more blinded and doubleblinded controlled studies with larger population sizes to, again, be able to say that they will definitely result in an improved rotator cuff repair.

\section{Compliance with Ethical Standards}

Conflict of interest The authors declare that they have no conflict of interest.

Open Access This article is distributed under the terms of the Creative Commons Attribution 4.0 International License (http:// creativecommons.org/licenses/by/4.0/), which permits unrestricted use, distribution, and reproduction in any medium, provided you give appropriate credit to the original author(s) and the source, provide a link to the Creative Commons license, and indicate if changes were made.

\section{References}

1. Weiss, L.J., et al., Management of rotator cuff injuries in the elite athlete. Curr Rev Musculoskelet Med. 2018: p. 1-11.

2. Vollans S, Ali A. Rotator cuff tears. Surgery (Oxford). 2016;34(3): 129-33.

3. Randelli P, Randelli F, Ragone V, Menon A, D'Ambrosi R, Cucchi $\mathrm{D}$, et al. Regenerative medicine in rotator cuff injuries. Biomed Res Int. 2014;2014:1-9.

4. Rothrauff BB, Pauyo T, Debski RE, Rodosky MW, Tuan RS, Musahl V. The rotator cuff organ: integrating developmental biology, tissue engineering, and surgical considerations to treat chronic massive rotator cuff tears. Tissue Eng B Rev. 2017;23(4):318-35.

5. Savin D, Meadows M, Verma N, Cole B. Rotator cuff healing: improving biology. Oper Tech Sports Med. 2017;25(1):34-40.

6. Jo CH, Shin JS, Shin WH, Lee SY, Yoon KS, Shin S. Platelet-rich plasma for arthroscopic repair of medium to large rotator cuff tears: a randomized controlled trial. Am J Sports Med. 2015;43(9):2102-10.

7. Pandey V, Bandi A, Madi S, Agarwal L, Acharya KKV, Maddukuri $\mathrm{S}$, et al. Does application of moderately concentrated platelet-rich plasma improve clinical and structural outcome after arthroscopic repair of medium-sized to large rotator cuff tear? A randomized controlled trial. J Shoulder Elb Surg. 2016;25(8):1312-22.

8. Hernigou P, Flouzat Lachaniette CH, Delambre J, Zilber S, Duffiet $\mathrm{P}$, Chevallier N, et al. Biologic augmentation of rotator cuff repair with mesenchymal stem cells during arthroscopy improves healing and prevents further tears: a case-controlled study. Int Orthop. 2014;38(9):1811-8.

9. Kim YS, Sung CH, Chung SH, Kwak SJ, Koh YG. Does an injection of adipose-derived mesenchymal stem cells loaded in fibrin glue influence rotator cuff repair outcomes? A clinical and magnetic resonance imaging study. Am J Sports Med. 2017;45(9):2010-8.

10. Barber FA, Burns JP, Deutsch A, Labbé MR, Litchfield RB. A prospective, randomized evaluation of acellular human dermal matrix augmentation for arthroscopic rotator cuff repair. Arthroscopy. 2012;28(1):8-15.

11. Carr AJ, Murphy R, Dakin SG, Rombach I, Wheway K, Watkins B, et al. Platelet-rich plasma injection with arthroscopic acromioplasty for chronic rotator cuff tendinopathy: a randomized controlled trial. Am J Sports Med. 2015;43(12):2891-7.

12. Malavolta EA, Gracitelli MEC, Ferreira Neto AA, Assunção JH, Bordalo-Rodrigues M, de Camargo OP. Platelet-rich plasma in rotator cuff repair: a prospective randomized study. Am J Sports Med. 2014;42(10):2446-54. 
13. Antuña S, et al. Platelet-rich fibrin in arthroscopic repair of massive rotator cuff tears: a prospective randomized pilot clinical trial. Acta Orthop Belg. 2013;79(1):25-30.

14. Kesikburun S, Tan AK, Yılmaz B, Yaşar E, Yazıcıoğlu K. Plateletrich plasma injections in the treatment of chronic rotator cuff tendinopathy: a randomized controlled trial with 1-year follow-up. Am J Sports Med. 2013;41(11):2609-16.

15. Rodeo SA, Delos D, Williams RJ, Adler RS, Pearle A, Warren RF. The effect of platelet-rich fibrin matrix on rotator cuff tendon healing: a prospective, randomized clinical study. Am J Sports Med. 2012;40(6):1234-41.

16. Weber S, Kauffman J, Katz S, Parise C, Weber S. Platelet-rich fibrin matrix in the management of arthroscopic repair of the rotator cuff: a prospective, randomized study. Arthroscopy. 2012;26(6):263-70.

17. Randelli P, Arrigoni P, Ragone V, Aliprandi A, Cabitza P. Platelet rich plasma in arthroscopic rotator cuff repair: a prospective RCT study, 2-year follow-up. J Shoulder Elb Surg. 2011;20(4):518-28.

18. Dolkart O, Chechik O, Zarfati Y, Brosh T, Alhajajra F, Maman E. A single dose of plateletrich plasma improves the organization and strength of a surgically repaired rotator cuff tendon in rats. Arch Orthop Trauma Surg. 2014;134(9):1271-7.

19. Lamplot JD, Angeline M, Angeles J, Beederman M, Wagner E, Rastegar F, et al. Distinct effects of platelet-rich plasma and BMP13 on rotator cuff tendon injury healing in a rat model. Am J Sports Med. 2014;42(12):2877-87.

20. Chung SW, Song BW, Kim YH, Park KU, Oh JH. Effect of plateletrich plasma and porcine dermal collagen graft augmentation for rotator cuff healing in a rabbit model. Am J Sports Med. 2013;41(12):2909-18

21. Wu Y, Dong Y, Chen S, Li Y. Effect of platelet-rich plasma and bioactive glass powder for the improvement of rotator cuff tendonto-bone healing in a rabbit model. Int J Mol Sci. 2014;15(12): 21980-91.

22. Randelli P, Arrigoni P, Ragone V, Aliprandi A, Cabitza P. Platelet rich plasma in arthroscopic rotator cuff repair: a prospective RCT study, 2-year follow-up. J Shoulder Elb Surg. 2011;20(4):518-28.

23. Antuña S, Barco R, Martinez Diez JM, Sanchez Marquez JM. Platelet-rich fibrin in arthroscopic repair of massive rotator cuff tears: a prospective randomized pilot clinical trial. Acta Orthop Belg. 2013;79(1):25-30.

24. Gomes JL, Da Silva RC, Silla LM, Abreu MR, Pellanda R. Conventional rotator cuff repair complemented by the aid of mononuclear autologous stem cells. Knee Surg Sports Traumatol Arthrosc. 2012;20(2):373-7.

25. Sevivas N, Teixeira FG, Portugal R, Araújo L, Carriço LF, Ferreira $\mathrm{N}$, et al. Mesenchymal stem cell secretome: a potential tool for the prevention of muscle degenerative changes associated with chronic rotator cuff tears. Am J Sports Med. 2017;45(1):179-88.

26. Degen RM, Carbone A, Carballo C, Zong J, Chen T, Lebaschi A, et al. The effect of purified human bone marrow-derived mesenchymal stem cells on rotator cuff tendon healing in an athymic rat. Arthroscopy. 2016;32(12):2435-43.

27. Barco R, Encinas C, Valencia M, Carrascal MT, García-Arranz M, Antuña S. Use of adipose-derived stem cells in an experimental rotator cuff fracture animal model. Revista Española de Cirugía Ortopédica y Traumatología (English Edition). 2015;59(1):3-8.

28. Park GY, Kwon DR, Lee SC. Regeneration of full-thickness rotator cuff tendon tear after ultrasound-guided injection with umbilical cord blood-derived mesenchymal stem cells in a rabbit model. Stem Cells Transl Med. 2015;4(11):1344-51.

29. Oh JH, Chung SW, Kim SH, Chung JY, Kim JY. 2013 Neer award: effect of the adipose-derived stem cell for the improvement of fatty degeneration and rotator cuff healing in rabbit model. J Shoulder Elb Surg. 2014;23(4):445-55.

30. Gulotta LV, Kovacevic D, Packer JD, Ehteshami JR, Rodeo SA. Adenoviral-mediated gene transfer of human bone morphogenetic protein-13 does not improve rotator cuff healing in a rat model. Am J Sports Med. 2011;39(1):180-7.

31. Gulotta LV, Kovacevic D, Packer JD, Deng XH, Rodeo SA. Bone marrow-derived mesenchymal stem cells transduced with scleraxis improve rotator cuff healing in a rat model. Am J Sports Med. 2011;39(6):1282-9.

32. Gulotta LV, Kovacevic D, Montgomery S, Ehteshami JR, Packer JD, Rodeo SA. Stem cells genetically modified with the developmental gene MT1-MMP improve regeneration of the supraspinatus tendon-tobone insertion site. Am J Sports Med. 2010;38(7):1429 37.

33. Gulotta LV, Kovacevic D, Ehteshami JR, Dagher E, Packer JD, Rodeo SA. Application of bone marrow-derived mesenchymal stem cells in a rotator cuff repair model. Am J Sports Med. 2009;37(11):2126-33.

34. Gomes JLE, et al. Conventional rotator cuff repair complemented by the aid of mononuclear autologous stem cells. Knee Surg Sports Traumatol Arthrosc. 2012;20(2):373-7.

35. Kim A, et al. Corneal stromal cells use both high- and lowcontractility migration mechanisms in 3-D collagen matrices. Exp Eye Res. 2012;318(6):741-52.

36. Romero A, Barrachina L, Ranera B, Remacha AR, Moreno B, de Blas I, et al. Comparison of autologous bone marrow and adipose tissue derived mesenchymal stem cells, and platelet rich plasma, for treating surgically induced lesions of the equine superficial digital flexor tendon. Vet J. 2017;224:76-84.

37. Gulotta LV, Rodeo SA. Growth factors for rotator cuff repair. Clin Sports Med. 2009;28(1):13-23.

38. Schwab LM, Blanch P, Young M. Autologous tenocyte implantation into shoulder tendon pathology in an elite swimmer. Physical Therapy in Sport. 2018;29:19-25.

39. Lenart BA, Martens KA, Kearns KA, Gillespie RJ, Zoga AC, Williams GR. Treatment of massive and recurrent rotator cuff tears augmented with a poly-1-lactide graft, a preliminary study. J Shoulder Elb Surg. 2015;24(6):915-21.

40. Cho C-H, Lee SM, Lee YK, Shin HK. Mini-open suture bridge repair with porcine dermal patch augmentation for massive rotator cuff tear: surgical technique and preliminary results. Clinics in orthopedic surgery. 2014;6(3):329-35.

41. Proctor CS. Long-term successful arthroscopic repair of large and massive rotator cuff tears with a functional and degradable reinforcement device. J Shoulder Elb Surg. 2014;23(10):1508-13.

42. Moffat KL, et al. Novel nanofiber-based scaffold for rotator cuff repair and augmentation. Tissue Eng Part A. 2008;15(1):115-26.

43. Burkhead, W.Z., S.C. Schiffern, and S.G. Krishnan. Use of graft jacket as an augmentation for massive rotator cuff tears. In Semin Arthroplasty. 2007. Elsevier.

44. Omae H, Steinmann SP, Zhao C, Zobitz ME, Wongtriratanachai P, Sperling JW, et al. Biomechanical effect of rotator cuff augmentation with an acellular dermal matrix graft: a cadaver study. Clin Biomech. 2012;27(8):789-92.

45. Thangarajah T, Henshaw F, Sanghani-Kerai A, Lambert SM, Blunn GW, Pendegrass CJ. The effectiveness of demineralized cortical bone matrix in a chronic rotator cuff tear model. J Shoulder Elb Surg. 2017;26(4):619-26.

46. Zheng Z, Ran J, Chen W, Hu Y, Zhu T, Chen X, et al. Alignment of collagen fiber in knitted silk scaffold for functional massive rotator cuff repair. Acta Biomater. 2017;51:317-29.

47. Huegel J, Kim DH, Cirone JM, Pardes AM, Morris TR, Nuss CA, et al. Autologous tendon-derived cell-seeded nanofibrous scaffolds improve rotator cuff repair in an age-dependent fashion. J Orthop Res. 2017;35(6):1250-7.

48. Islam A, Bohl MS, Tsai AG, Younesi M, Gillespie R, Akkus O. Biomechanical evaluation of a novel suturing scheme for grafting load-bearing collagen scaffolds for rotator cuff repair. Clin Biomech. 2015;30(7):669-75. 
49. Chang $\mathrm{CH}$, Chen $\mathrm{CH}, \mathrm{Su} \mathrm{CY}$, Liu HT, Yu CM. Rotator cuff repair with periosteum for enhancing tendon-bone healing: a biomechanical and histological study in rabbits. Knee Surg Sports Traumatol Arthrosc. 2009;17(12):1447-53.

50. Funakoshi T, Majima T, Iwasaki N, Suenaga N, Sawaguchi N, Shimode K, et al. Application of tissue engineering techniques for rotator cuff regeneration using a chitosanbased hyaluronan hybrid fiber scaffold. Am J Sports Med. 2005;33(8):1193-201.

51. Nicholson GP, Breur GJ, Van Sickle D, Yao JQ, Kim J, Blanchard CR. Evaluation of a cross-linked acellular porcine dermal patch for rotator cuff repair augmentation in an ovine model. J Shoulder Elb Surg. 2007;16(5):S184-90. 